\title{
ARTIGO ORIGINAL Qualidade de vida de uma amostra de profissionais de educação física
}

\author{
Quality of life in a sample of physical educators \\ José Carlos Souza', Domingos Sávio da Costa²
}

\section{RESUMO}

\section{Palavras-chave}

Qualidade de vida, SF-36, educador físico.

\section{Keywords}

Quality of life, SF-36, physical educator.
Objetivo: Avaliar a QV de professores de educação física. Método: Quantitativo e de corte transversal. Uma amostra de 200 professores preencheu voluntariamente o termo de consentimento, o questionário sociodemográfico e o MOS (SF-36). Foi aplicado o teste não paramétrico da mediana de Mood, com 95\% de confiabilidade. Resultados: Os domínios que tiveram associação significativa com o sexo foram dor, capacidade funcional e saúde mental. As dimensões correlacionadas com a idade foram a capacidade funcional e os aspectos físicos. Conclusão: A presença de quadra na escola foi um fator positivo para a QV dos professores, ao contrário do tempo de docência.

\begin{abstract}
Objective: To assess the QOL of physical educators. Method: A quantitative and cross-sectional study. A sample of 200 teachers completed the informed consent term, the sociodemographic questionnaire and the MOS (SF-36). The Nonparametric Mood's Median Test was used, with a 95\% reliability. Results: The areas that were significantly associated with sex were pain, functional capacity and mental health. The dimensions correlated with age were the functional capacity and mental health. Conclusion: The square presence was a positive and teaching time a negative $Q O L$ predictor.
\end{abstract}

\section{INTRODUÇÃO}

O profissional de educação física exerce suas funções dirigidas à educação e à saúde, com atividades voltadas à sociedade, em locais como escolas, clubes, academias, hospitais, clínicas, entre outros. Ele trabalha com crianças, adolescentes, jovens, adultos e pessoas da melhor idade, com o intuito de proporcionar educação, lazer e saúde por meio da atividade física, contribuindo para a qualidade de vida (QV) da sociedade. Acredita-se que, para esse profissional desenvolver suas funções da melhor forma possível, seja necessário estar gozando de plena saúde'.

Conforme Kimura², QV é um conceito multidimensional e subjetivo e, apesar das controvérsias quanto ao real significado dessa expressão, há um consenso entre muitos autores quanto à inclusão de aspectos relacionados à capacidade

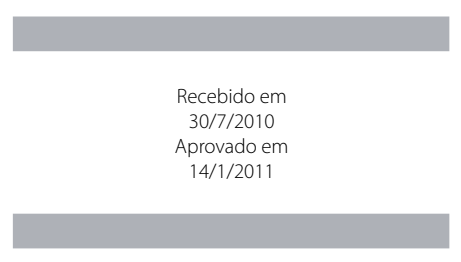

1 Universidade Estadual de Campinas (Unicamp), Faculdade de Medicina de Lisboa, Universidade Católica Dom Bosco (UCDB), Campo Grande, MS.

2 Universidade Gama Filho, UCDB.

Endereço para correspondência: José Carlos Souza

Rua Theotônio Rosa Pires, 88, Vila Rosa Pires - 79004-340 - Campo Grande, MS

Telefone: (67) 3325-0990 / Telefax: (67) 9981-6271

E-mail: josecarlossouza@uol.com.br 
funcional, às funções fisiológicas, ao comportamento afetivo e emocional, às interações sociais, ao trabalho e à situação econômica, centrados na avaliação subjetiva dos indivíduos. Dessa forma, a QV se apresenta como um constructo multifatorial, muito mais amplo do que a presença ou ausência de saúde. Nahas ${ }^{3}$ explica que os fatores que determinam a QV das pessoas são muitos; a combinação deles resulta numa rede de fenômenos e situações que pode abstratamente ser chamada de QV. Geralmente, estão associados a ela preditores como estado de saúde, longevidade, satisfação no trabalho, salário, lazer, relações familiares, disposição, prazer e espiritualidade. "Num sentido mais amplo, QV pode ser uma medida da própria dignidade do homem, pois pressupõe o atendimento das necessidades humanas fundamentais" ${ }^{\prime \prime}$.

Muitos pesquisadores tentam um equilíbrio entre uma abordagem da QV que enfatize o indivíduo e uma abordagem particular e nomotética que enfatize o grupo e o geral. Alguns deles desenvolveram medidas psicométricas e instrumentos individualizados ou gerados pelos pacientes que permitem que o respondente escolha os aspectos da vida a serem incluídos na avaliação da QV. Mas, geralmente, os métodos de avaliação são padronizados de forma que as escalas de resposta sejam uniformes durante toda a administração do instrumento, como é o caso do MOS-SF-364.

A QV no trabalho consiste em fatores que melhoram as condições dele, com extensão a todas as funções de qualquer natureza e nível hierárquico. Devem-se levar em conta as variáveis comportamentais e organizacionais que venham, juntamente com as políticas de recursos humanos condizentes, humanizar o emprego, obtendo-se um resultado satisfatório tanto para os empregados como para a organização5.

Nesse contexto objetivou-se, nesta pesquisa, avaliar a QV relacionada à saúde de uma amostra de profissionais de educação física que atuam na rede pública estadual e municipal de ensino.

\section{MÉTODO}

O método foi quantitativo, exploratório, descritivo, comparativo e de corte transversal. A pesquisa foi aprovada pelo Comitê de Ética em Pesquisa da UCDB.

A amostragem foi casual e por conveniência em uma população total de 765 professores, sendo 415 deles das 87 escolas públicas municipais existentes e 350 professores das 84 escolas públicas estaduais. A amostra consistiu de 200 participantes, que representou um percentual de $26 \%$ da população total de professores de Educação Física de Campo Grande, MS.

Foi aplicado um questionário sociodemográfico que incluía as variáveis idade, sexo, escola, nível salarial, estado civil, ter ou não filhos, curso de atualização, carga horária semanal, atuação fora da escola pública, atuação em outra área, estrutura física dos locais em que atuava e tempo de atuação como professor. Aplicou-se, também, o Medical Outcomes Study 36item Short Form Health Survey (SF-36), que é um questionário multidimensional formado por 36 itens, englobados em oito escalas ou componentes: Capacidade Funcional (dez itens), Aspectos Físicos (quatro itens), Dor (dois itens), Estado Geral de Saúde (cinco itens), Vitalidade (quatro itens), Aspectos Sociais (dois itens), Aspectos Emocionais (três itens) e Saúde Mental (cinco itens) e mais uma questão de avaliação comparativa entre as condições de saúde atual e a de um ano atrás. Avalia tanto aspectos negativos da saúde (doença ou enfermidade) como os aspectos positivos (bem-estar), apresentando um escore final de 0 a 100, no qual 0 corresponde a pior estado geral de saúde e 100 a melhor estado de saúde, sendo analisada cada dimensão em separado ${ }^{6,7}$. Foi realizado um estudo piloto com três professores de educação física para averiguar a adaptação dos instrumentos à população estudada.

Os questionários foram enviados para todos os professores de Educação Física das escolas públicas de Campo Grande, MS, por correspondência, utilizando-se a mala-direta das Secretarias Municipal e Estadual de Educação. Os questionários foram enviados aos diretores de todas as escolas públicas, acompanhados de ofícios assinados pelos representantes das secretarias. Os diretores ficaram responsáveis por distribuir os instrumentos aos professores de Educação Física da sua escola e, após o seu preenchimento, devolvê-los às suas secretarias.

Foi enviado um envelope grande, lacrado e personalizado, a cada professor de Educação Física, com dois envelopes dentro, um pardo e outro branco, sem nenhuma identificação. O envelope branco continha o Termo de Consentimento e o envelope pardo, o questionário sociodemográfico e o SF-36. Após serem preenchidos, deveriam ser recolocados no mesmo envelope e devolvidos às suas secretarias. Os questionários foram enviados e recebidos, preenchidos, entre maio e junho de 2008.

$\mathrm{Na}$ análise estatística dos dados, foi aplicado o teste não paramétrico da mediana de Mood, com nível de confiabilidade de $95 \%$.

\section{RESULTADOS}

Os dados demográficos e profissionais dos professores de educação física amostrados estão na tabela 1.

A tabela 2 apresenta as variáveis sociodemográficas que exibiram diferenças estatisticamente significativas e os domínios do SF-36.

As variáveis sociodemográficas e profissionais que não apresentaram diferença significativa com nenhum domínio do SF-36 foram o tipo de escola, renda, estado civil, atualização, carga horária, atuação fora da escola e atuação fora da área. Esse resultado significa que nenhum desses fatores interferia na QV dos profissionais de educação física quando comparados entre si. 
Tabela 1. Perfil sociodemográfico e dados profissionais dos educadores físicos

\begin{tabular}{|c|c|c|c|}
\hline \multicolumn{2}{|c|}{ Variável } & \multirow{2}{*}{$\begin{array}{l}\text { Quantidade } \\
73\end{array}$} & \multirow{2}{*}{$\begin{array}{l}\text { Percentual (\%) } \\
36,87\end{array}$} \\
\hline Idade & Até 30 anos & & \\
\hline & De 30 a 40 anos & 69 & 34,85 \\
\hline & Acima de 40 anos & 56 & 28,28 \\
\hline \multirow[t]{2}{*}{ Sexo } & Feminino & 101 & 51,79 \\
\hline & Masculino & 94 & 48,21 \\
\hline \multirow[t]{3}{*}{ Tipo de escola } & Ambas & 45 & 23,56 \\
\hline & Estadual & 47 & 24,61 \\
\hline & Municipal & 99 & 51,83 \\
\hline \multirow[t]{3}{*}{ Renda } & 1 & 53 & 27,60 \\
\hline & 2 & 101 & 52,60 \\
\hline & 3 & 38 & 19,79 \\
\hline \multirow[t]{3}{*}{ Estado civil } & Casado & 95 & 48,72 \\
\hline & Solteiro & 80 & 41,03 \\
\hline & Outros & 20 & 10,26 \\
\hline \multirow[t]{2}{*}{ Filhos } & Não & 90 & 45,23 \\
\hline & $\operatorname{Sim}$ & 109 & 54,77 \\
\hline \multirow[t]{2}{*}{ Atualização } & Graduação & 69 & 34,67 \\
\hline & Pós-graduação & 130 & 65,33 \\
\hline \multirow[t]{2}{*}{ Carga horária semanal } & Até 40 horas & 171 & 86,80 \\
\hline & Acima de 40 horas & 26 & 13,20 \\
\hline \multirow[t]{2}{*}{ Atuação fora da escola } & Não & 140 & 70,35 \\
\hline & Sim & 59 & 29,65 \\
\hline \multirow[t]{2}{*}{ Atuação fora da área } & Não & 162 & 82,23 \\
\hline & Sim & 35 & 17,77 \\
\hline \multirow[t]{2}{*}{ Escola possui quadra? } & Não & 17 & 8,81 \\
\hline & $\operatorname{sim}$ & 176 & 91,19 \\
\hline \multirow[t]{3}{*}{ Tempo atuação } & Até 5 anos & 92 & 46,70 \\
\hline & De 5 a 10 anos & 35 & 17,77 \\
\hline & Acima de 10 anos & 70 & 35,53 \\
\hline
\end{tabular}

Com relação à idade dos profissionais, nas dimensões Capacidade Funcional e Limitações de Aspectos Físicos, quanto menor a idade, melhor era a QV nesses domínios.

As mulheres apresentaram índices piores de QV em relação aos homens nas dimensões Capacidade Funcional, Dor e Saúde Mental. Já em relação à variável se o profissional possuía filhos, os que não os possuíam estavam com QV meIhor no domínio Capacidade Funcional.
Tabela 2. Variáveis sociodemográficas que exibiram diferenças estatisticamente significativas e os domínios do SF-36

\begin{tabular}{lll}
\hline Variável & Dimensão & $P$ \\
\hline Idade & Capacidade funcional & $<0,001$ \\
& $\begin{array}{l}\text { Limitação de aspectos } \\
\text { físicos }\end{array}$ & 0,015 \\
& Capacidade funcional & 0,028 \\
Sexo & Dor & 0,020 \\
& Saúde mental & 0,010 \\
Filhos? & Capacidade funcional & 0,020 \\
Escola possui quadra? & Estado geral de saúde & 0,018 \\
Tempo de atuação & Capacidade funcional & $<0,001$ \\
& Dor & 0,014 \\
& Aspectos sociais & 0,006 \\
& Limitação de aspectos & 0,046 \\
& emocionais & \\
\hline
\end{tabular}

A variável se a escola possuía quadra foi significativa em relação ao domínio Estado Geral de Saúde, e os profissionais que trabalhavam em escolas que não possuíam quadra apresentaram piores índices de QV nesse componente.

O tempo de atuação do profissional foi significativo nas dimensões Capacidade Funcional, Dor, Aspectos Sociais e Limitações de Aspectos Emocionais; em todas essas dimensões, os profissionais com mais tempo de trabalho possuíam piores índices de QV.

\section{DISCUSSÃO}

Houve equilíbrio entre os professores avaliados neste estudo com relação ao sexo, contrapondo com Rocha e Fernandes ${ }^{8}$, que realizaram um estudo com o objetivo de avaliar a QV dos professores do ensino fundamental do município de Jequié, BA, utilizando o SF-36, e constataram que a maioria dos profissionais era de mulheres $(95,60 \%)$. Pereira ${ }^{9}$ realizou um estudo com o objetivo de identificar e analisar a percepção de QV, condições de trabalho e estresse relacionado ao trabalho de professores de educação básica no município de Florianópolis, SC, e verificou, também, que mais de $80 \%$ da amostra eram de mulheres. Conforme o mesmo autor, esse resultado confirma que a escola é um espaço de trabalho em que ainda predominam as mulheres, diverso da maioria das profissões; para ele, esse aspecto faz com que o trabalho e qualquer análise da saúde de profissionais apresentem características singulares.

Na comparação da QV em relação ao sexo, foram encontradas diferenças significativas nos domínios Dor, Capacida- 
de Funcional e Saúde Mental, e as mulheres obtiveram escores piores que os homens. Rocha e Fernandes ${ }^{8}$ justificaram esse fato pela dupla jornada exercida pelas mulheres, que se ocupam das atividades do lar e da profissão.

O domínio Aspecto Social envolve a interação familiar, com os amigos e a comunidade. Gonçalves e cols. ${ }^{10}$ enfocaram que, além das condições físicas, as relações entre os professores, os alunos e a direção da escola podem ser determinantes importantes para a saúde e propuseram que as análises com essa população sejam realizadas de forma mais ampla e interdisciplinar.

Os resultados da comparação entre a renda dos professores e os domínios analisados não apontaram diferenças significativas. As médias mais elevadas foram na capacidade funcional, com 90,29 para quem possuía renda de 1 a 3 salários-mínimos (SM), 87,24 para 3 a 5 SM e 91,45 para renda acima de 5 SM. Esse resultado apresenta distorção em comparação ao relatado por Pereira ${ }^{9}$, segundo o qual a grande desvalorização salarial e o pouco incentivo para a educação continuada são questões comuns encontradas nos estudos $^{10-12}$. Conforme aborda Lapo e Bueno ${ }^{13}$, os professores em muitas realidades formam uma das categorias com menores salários e isso está diretamente relacionado à insatisfação e ao abandono do trabalho docente, com o direcionamento para outras ocupações.

Segundo Silvany Neto et al..$^{14}$ e Esteve ${ }^{15}$, a atividade docente, a longo prazo, pode resultar em patologias musculoesqueléticas e psicológicas, muitas vezes relacionadas a quadros alérgicos intensos, podendo acarretar absenteísmos. Laranjeira ${ }^{16}$ destaca, também, o problema do presenteísmo. Embora o trabalho docente tenha sofrido alterações ao longo do tempo, o professor não teve condições de criar meios para se adaptar às mudanças, levando ao surgimento de desequilíbrios na estrutura corporal.

A correlação entre a carga horária de trabalho dos professores e os domínios de QV não mostrou nenhuma diferença significativa. Isso contradiz os achados de Pereira ${ }^{9}$, nos quais os professores com maior carga horária apresentaram índices piores de QV. Considerando que o profissional de Educação Física apresenta conhecimentos sobre a importância da atividade física para sua saúde cardiovascular, morfológica e mental, bem como tem autonomia para prescrever sua própria rotina de exercícios, ele certamente será um indivíduo mais ativo, prevenindo o surgimento de disfunções hipocinéticas. Diversos estudos confirmam que cargas horárias maiores estão associadas tanto com pior QV quanto com o acometimento de patologias 12,17-19. $^{2}$.

Da mesma forma, Codo ${ }^{17}$ verificou forte associação entre o tempo de docência e maiores prevalências de burnout, sugerindo que o tempo de aposentadoria dos professores seja questionado. Observa-se que o tempo de atuação dos professores, tanto dos que trabalham em sala de aula como os que atuam fora, gera um desgaste semelhante. No entanto, acredita-se que, por causa das atividades práticas realizadas pelos professores de Educação Física, muitas vezes junto com seus alunos, estas possam atenuar os desgastes físico e mental.

\section{CONCLUSÃO}

As mulheres apresentaram pior QV em relação aos homens. A infraestrutura da escola onde trabalhava, como a existência de quadra, foi um fator positivo para a QV dos professores, com relação ao seu estado geral de saúde. Por outro lado, quanto mais tempo de trabalho na docência, pior era a QV dos professores, no que dizia respeito à sua capacidade funcional, dor, aspectos sociais e emocionais.

A presente amostra foi pequena e não representativa dos profissionais de Educação Física. Novos estudos, mais amplos e representativos, devem ser realizados, inclusive com outras classes profissionais, a fim de se compararem os resultados e se proporem ações preventivas que visem, em última análise, à melhoria da QV da população.

\section{REFERÊNCIAS}

1. Wong WS, Chan STM, Fung VBK, Fielding R. The differential mediating effects of pain and depression on the physical and mental dimension of quality of life in Hong Kong Chinese adults. Health Qual Life Outcomes. 2010;8:1-6.

2. Kimura M. Tradução para o português e validação do "Quality of life index" de Ferrans e Powers [tese de livre-docência]. São Paulo: Escola de Enfermagem da Universidade de São Paulo; 1999.

3. Nahas MV. Atividade física, saúde e qualidade de vida. 2a ed. Londrina: Midiograf; 2001.

4. Fleck MPA, et al. A avaliação de qualidade de vida: guia para profissionais da saúde. Porto Alegre: Artmed; 2008.

5. Queiroz IS. Fatores que influenciam a qualidade de vida no trabalho: um estudo de caso no Instituto Médico Legal de Campo Grande (MS). Campo Grande: UFMS; 2005.

6. Ciconelli RM. Tradução para o português e validação do questionário genérico de avaliação de qualidade de vida [tese]. São Paulo: Universidade Federal de São Paulo (EPM), Departamento de Ciências Médicas; 1997.

7. Ware JE, Sherbourne CD. The MOS 36-Item Short-Form Health Survey (SF-36): I. Conceptual framework and item selection. Med Care. 1992;30(6):473-83.

8. Rocha VM, Fernandes MHJ. Qualidade de vida de professores do ensino fundamental: uma perspectiva para a promoção da saúde do trabalhador. J Bras Psiquiatr. 2008;57(1):23-7.

9. Pereira EF. Qualidade de vida e condições de trabalho de professores de educação básica do município de Florianópolis - SC [dissertação]. Florianópolis: Universidade Federal de Santa Catarina; 2008.

10. Gonçalves $C G 0$, Penteado RZ, Silvério KCA. Fonoaudiologia e saúde do trabalhador: a questão da saúde vocal do professor. Saúde em Revista. 2005;7(15):45-51.

11. Gasparini SM, Barreto SM, Assunção AA. 0 professor, as condições de trabalho e os efeitos sobre sua saúde. Educação e Pesquisa. 2005;31(2):189-99.

12. Reis EJEB, Araújo TM, Carvalho FM, Barbalho L, Silva M0. Docência e exaustão emocional. Educação \& Sociedade. 2006;27(94):229-53.

13. Lapo FR, Bueno B. Os professores, desencanto com a profissão e abandono do magistério. Cadernos de Pesquisa. 2003;118:65-88.

14. Silvany Neto AM, Araújo TM, Dultra FRD, et al. Condições de trabalho e saúde de professores da rede particular de ensino de Salvador, Bahia. Rev Baiana Saúde Pública. 2002;24:42-56. 
15. Esteve JM. 0 mal-estar docente: a sala de aula e a saúde dos professores. Bauru: EDUSC; 1999.

16. Laranjeira CA. El contexto organizativo y la experiencia de stress: una perspectiva integrativa. Rev Salud Publica (Bogota). 2009;11(1):123-33.

17. Codo W. Educação: carinho e trabalho. Petrópolis: Vozes; 1999.
18. Fuess VLR, Lorenz MC. Disfonia em professores do ensino municipal: prevalência e fatores de risco. Rev Bras Otorrinolaringologia. 2003;69(6):807-12.

19. Rocha SSL, Felli VEA. Qualidade de vida no trabalho docente em enfermagem. Rev Lat-Am Enferm. 2004;12(1):28-35. 